\title{
Música e sintaxe: \\ implicações para a \\ subjetividade e a \\ ordem social
}

Álvaro Neder

(IFRJ)

RESUMO: Este artigo examina algumas consequências da organização do discurso musical, notadamente a sintaxe, para a subjetividade. Um destaque especial é dado à sintaxe tonal, como um poderoso modelo de condicionamento, e a sua dissolução pelas experiências atonais do início do século XX, especialmente a criação tão pioneira quanto insólita representada pelas Seis Bagatelas para Quarteto de Cordas Op. 9, de Anton Webern. O conceito de chora semiótico, desenvolvido pela psicanalista e crítica literária Julia Kristeva, torna possível teorizar o vínculo entre música e subjetividade. conduzindo à compreensão do papel da música na manutenção ou transformação da ordem simbólica.

PALAVRAS-CHAVE: discurso musical; subjetividade; intertextualidade; teoria literária; Webern

MUSIC AND SYNTAX: IMPLICATIONS FOR SUBJECTIVITY AND SOCIAL ORDER

ABSTRACT: This essay examines some consequences of the organization of musical discourse, notably syntax, to subjectivity. A special focus is given to tonal syntax, as a powerful conditioning model, and to its dissolution by the atonal experiences of the early $20^{\text {th }}$ century, especially the seminal and uncanny Six Bagatelles for String Quartet, Op. 9, by Anton Webern. The concept of semiotic chora, developed by psychoanalyst and literary critic Julia Kristeva, makes it possible to theorize the link between music and subjectivity, yielding to the understanding of the role of music in the maintenance or transformation of symbolic order.

KEYWORDS: musical discourse; subjectivity; intertextuality; literary theory; Webern 
As relações entre música, significação e subjetividade vêm ocupando críticos, teóricos e produtores ocidentais desde a Antiguidade Clássica, inclusive pensadores que, como Hanslick, buscaram negar tais relações (com resultados passíveis de questionamento; a propósito, ver Neder, 2010, p. 187). Entre os gregos, diferentes sequências de alturas de som (escalas) já eram organizadas em um sistema (modal), que dotava de sentido as organizações sonoras, os modos. Segundo a Política de Aristóteles, e a República de Platão, os modos podiam ser viris (dório), tristes e graves (mixolídio), entusiasmantes (frígio), enlanguescedores e dionisíacos. A música era entendida como imitação dos estados da alma, e, como consequência, constituiria poderoso indutor dos mesmos estados em quem a ouvisse (Aristóteles, 1988, p. 467). Consequentemente, a música podia tanto ser útil à pólis, auxiliando no trabalho pedagógico do cidadão e fortalecendo o tecido social, quanto poderia ser sua ruína e esfacelamento. Como decorrência, estabeleceu-se uma cisão entre a música cívica e a música dionisíaca. Música cívica era aquela que privilegiava as alturas musicais, entendidas como tendo valor cognitivo mais alto e conducentes à ordem e à razão. Música dionisíaca era a música rítmica, ligada ao transe. Esta dicotomia, uma vez estabelecida, percorreria toda a história da civilização ocidental.

O sistema modal dá lugar ao sistema tonal na passagem do feudalismo para o capitalismo. Uma das maneiras possíveis de definir o sistema tonal é dizer que, neste sistema, a sintaxe musical - uma estrutura que organiza o tempo e o "espaço" musicais (a organização sintagmática dos elementos do discurso musical e a disposição das notas no espectro das frequências) - adquiriu uma força jamais imaginada pelo modal. Com isto quero dizer que o sistema virtual de relações, que rege a expectativa por sons que se sucedem na dimensão temporal, adquiriu uma maior autonomia em relação aos sons em sua concretude. A atenção do ouvinte foi ainda mais desviada da superfície sensual do som para as estruturas profundas da música: a mútua atração relativa dos elementos musicais dentro da gramática tonal, chamados de funções, passou a ser o foco da escuta; e a música passou a ser um sistema de expectativas confirmadas, suspensas ou negadas. 
Enquanto na música modal a tônica permanece, no mais das vezes, constante, e os outros graus se sucedem sem determinar a direção do movimento harmônico, na música tonal a situação se inverte. Agora, a tônica é continuamente substituída por outras tônicas através do processo de modulação, e para que isso fosse possível tornou-se necessário que certas estruturas (função dominante), feitas de elementos sonoros em tensão (dissonância), resolvessem-se em outras estruturas (funções tônica ou subdominante). Com isso, os sons perderam sua autonomia; nossa escuta, socializada segundo as regras do sistema tonal, tornou-se relacional, ao invés de concreta ${ }^{1}$. Uma nota $/ \mathrm{b} /$, executada no tom de $/ \mathrm{C} /$, provoca uma forte tensão e a expectativa de sua resolução na nota /c/. Já no tom de /B/, a mesma nota /b/ produz a sensação do mais absoluto repouso e estabilidade. Quaisquer modificações nos componentes acústicos não produzirão qualquer alteração no sentido tonal desta nota. Podemos executá-la com instrumentos de diferentes ataques (um trompete ou uma flauta), intensidades (um piano ou um violão), timbres (uma flauta ou um violino), que o sentido será o mesmo. O mesmo processo que ocorre com uma nota musical também ocorre com unidades estruturais maiores: acordes, motivos, frases, seções.

Mais intrigante ainda: uma peça composta para um instrumento dotado de grande poder de sustentação de som, como um violino, pode ser transcrita para um instrumento de pouquíssimo sustain, como um violão, sem que deixemos de compreendê-la. Uma nota concebida para durar quatro tempos recebe uma execução em que dura um tempo apenas (o restante de seu valor sendo preenchido pelo silêncio), e isto não impede que reconheçamos a peça: seu sentido é mantido intacto. A razão para isto é que o sistema métrico (que é complementar ao sistema tonal) também é relacional: instituindo uma fôrma rígida em que um número invariável de pulsos delimita uma unidade de medida denominada de compasso, o sistema métrico limita nossa percepção temporal de uma nota à sua posição no compasso. Portanto, desde que o ataque da nota se dê no ponto preciso onde deve ocorrer, no âmbito do compasso, o seu release (a terminação do som, afetando sua duração) não importa para a formação do

\footnotetext{
${ }^{1}$ A ideia de considerar a autonomização das dimensões temporais e frequenciais do sistema tonal através da sintaxe é tomada de Grauer, 2006.
} 
sentido. Não se deve minimizar a importância deste fato, que anula a tremenda diferença entre um som - qualquer som - e o silêncio. Percebemos então que existe uma simetria e um mútuo reforço entre as hierarquias frequenciais e temporais da música tonal. Com isto, pode-se dizer que, com o sistema tonal, a escuta semiótica (relacional) foi reforçada, às expensas da escuta acústica. Uma estrutura rígida, representada pelas relações sistemáticas métricas e tonais, condiciona, fortemente, nossa percepção do sentido musical. No entanto, como elemento virtual, ela é percebida apenas com dificuldade. Esta estrutura é a sintaxe musical. “Com cada nota roubada de seu 'peso' temporal [e acústico], o tempo [e o som são] experienciado[s] racionalmente, isto é, em termos de um código ideologicamente determinado, puramente conceitual” (Grauer, 2006).

Existe uma evidente relação entre a sintaxe musical e a sintaxe verbal. Tanto a música quanto a linguagem utilizam o meio sonoro, e ambas possuem sistemas de notação, de onde se abstraem seus elementos e relações. Muitas músicas apresentam certas relações estruturais que assemelham-se à linguagem, o que originou a metalinguagem da análise musical, e suas descrições tomadas da linguística: "períodos" ou "sentenças", "membros de frase", "frases", que são delimitadas por "respirações" ou "cadências" (que atuam como vírgulas e pontos finais) e assim por diante. Segundo Bent e Pople (2006), a definição desta metalinguagem deu-se a partir de 1782, com o trabalho do teórico H. C. Koch, Versuch einer Anleitung zur Composition (1782-93), que

estabelece uma moldura hierárquica na qual "segmentos" ou "incisos" de dois compassos (vollkommene Einschnitte) combinam-se em pares para formar "frases" de quatro compassos (Sätze), que, por sua vez, combinam-se para formar "períodos" (Perioden).

A música tradicional é, portanto, organizada de acordo com princípios bastante similares aos da linguagem verbal tradicional, apenas faltando-lhe a primeira articulação (organização de fonemas em, p. ex., morfemas), isto é, o nível semântico. No entanto, a música tradicional opera ao nível da segunda articulação (fonemas) e da sintaxe, tal como a linguagem. E também é organizada hierarquicamente. As relações entre a linguagem verbal e a musical trazem, 
portanto, a ordem simbólica para o primeiro plano. Estes três elementos são inseparáveis: a sintaxe musical, associada desde o início à sintaxe verbal, está também subordinada à ordem simbólica, tornando-se, assim, guardiã desta ordem. Esta é a razão, argutamente intuída, das preocupações de Platão em relação à integridade das formas musicais tradicionais:

. . nunca se abalam os gêneros musicais sem abalar as leis mais altas da cidade ... Logo, o posto de guarda deve-se erigi-lo neste lugar: na música. . . . [É] por aí que a inobservância das leis facilmente se infiltra, passando desapercebida. . . . e como quem não faz nada de mal. Nada mais faz . . . do que se introduzir aos poucos, deslizando mansamente pelo meio dos costumes e usanças. Daí deriva, já maior, para as convenções sociais; das convenções passa às leis e às constituições com toda a insolência . . . até que, por último, subverte todas as coisas na ordem pública e na particular". (Platão, 1980, p. 169-70)

É singular a correlação existente entre os efeitos e consequências da sintaxe verbal e musical. Ambas estão ligadas ao recalque de um movimento que, no entanto, luta permanentemente para ver-se livre destas amarras. A propósito deste movimento diz Mallarmé, citado por Kristeva:

indiferente à linguagem, enigmático e feminino, este espaço subjacente à escritura é rítmico, irredutível à sua tradução verbal inteligível; é musical, anterior ao julgamento, mas retido por apenas uma garantia - a sintaxe. (Mallarmé apud Kristeva, 1974, p. 29)

A este espaço rítmico, musical, anterior ao julgamento, mas reprimido pela sintaxe, Kristeva denomina de o semiótico (que não deve ser confundido com a ciência dos signos, a semiótica). O semiótico corresponde à fase "pré-edípica" descrita pela psicanalista Melanie Klein, como explica Kristeva: “Os processos que ela descreve para esta fase correspondem . . . ao que denominamos o semiótico por oposição ao simbólico, [que é] subjacente a ele e o condiciona" (Kristeva, 1974, pp. 26-7). Trata-se “de uma funcionalidade pré-verbal, que ordena as relações entre os corpos (em vias de se constituir, propriamente, como corpos), os objetos, e os protagonistas da estrutura familial" (Kristeva, 1974, p. 29). 
Para uma definição mais extensa do semiótico, é conveniente dar a voz à própria Kristeva. Segundo a autora, o uso etimológico preponderante do termo semiótico

implica em uma distinção, que nos permite conectá-lo a uma modalidade precisa no processo de significação. Esta modalidade é aquela para a qual a psicanálise freudiana aponta ao postular não apenas a facilitação e a disposição estruturante das pulsões, mas também os assim chamados processos primários que deslocam e condensam tanto as energias como sua inscrição. Quantidades discretas de energia movem-se através do corpo do sujeito que ainda não está constituído como tal e, no curso de seu desenvolvimento, são arranjadas de acordo com as várias limitações impostas a este corpo - desde sempre envolvido em um processo semiótico - por estruturas sociais e familiais. Desta forma, as pulsões, que são tanto cargas de "energia" quanto marcas "psíquicas", articulam o que chamamos uma chora: uma totalidade não-expressiva formada pelas pulsões e suas estases em uma motilidade que é tão plena de movimento quanto regulada. (Kristeva, 1974, p. 22-3)

Em outras palavras, as pulsões - já ambiguamente opostas, simultaneamente assimiladoras e agressivas, porém predominantemente destrutivas - envolvem as funções semióticas pré-edipianas e as descargas energéticas que conectam e orientam o corpo do bebê em direção ao da mãe. 0 corpo da mãe é, portanto, aquilo que medeia a lei simbólica que organiza as relações sociais, e se torna o princípio ordenador do chora semiótico. Retidas por limitações impostas pelas estruturas sociais e biológicas, as pulsões sofrem estases, produzindo descontinuidades nos vários suportes materiais suscetíveis de semiotização: voz, gestos, cores. Unidades e diferenças fônicas (mais tarde fonêmicas), cinéticas e cromáticas são as marcas destas estases. Estas marcas são organizadas, de acordo com sua semelhança ou oposição, por meio de deslocamentos ou condensações. Ao mesmo tempo, partes do corpo do bebê (os esfíncteres glotal e anal, por exemplo) são articuladas entre si ou entre si e os protagonistas familiares em modulações vocais rítmicas e intonacionais. Assim, o semiótico é entendido como uma modalidade psicossomática, não simbólica, do processo significante, anterior ao signo e à sintaxe, que articula as pulsões aos objetos e, mais tarde, à ordem simbólica. Em razão deste estatuto, Kristeva pode 
estudar a relação motivada (pelas pulsões) entre significante e significado no texto poético, e a destruição da sintaxe verbal pelo semiótico.

Quanto à categoria lacaniana do simbólico (que engloba a sintaxe e todas as categorias linguísticas), é descrito por Kristeva como "um efeito social da relação com o outro, estabelecido através das limitações objetivas constituídas pelas diferenças biológicas, entre as quais as sexuais, e pelas estruturas familiais dadas concretamente e historicamente (Kristeva, 1974, p. 29). Toda atividade humana coloca em movimento uma dialética entre o simbólico e o semiótico. Nenhum sistema significante (nem mesmo a música, como estamos vendo) é livre do simbólico: a ocorrência excepcional da anulação do simbólico implica em psicose. Portanto, existe uma relação necessária entre o simbólico e o sujeito capacitado à relação intersubjetiva, social. Kristeva explora esta relação através da fenomenologia husserliana, que a autora postula estar na base da linguística, da semiótica e do estruturalismo. A separação entre sujeito e objeto, fundamental para estas ciências e método, tal como descrita por Husserl, implica em um Ego transcendental ${ }^{2}$, uma consciência sempre presente a si mesma. A sintaxe, para Husserl, portanto, é um produto do Ego transcendental consciente ou intencional, "que julga ou fala, e, simultaneamente, coloca como espúrio tudo o que é heterogêneo à sua consciência" (Kristeva, 1974, p. 30-1). Portanto, o semiótico não é o Sentido (Sinn [ale.], meaning [ing.], sens [fr.]) husserliano; é anterior a ele, e não é cognitivo, no sentido de um sujeito constituído, cognoscente. Ao contrário, o sujeito husserliano está sempre presente a si, e não perde de vista o objeto desde sempre já destacado dele, pois que apóia-se sobre leis transcendentais, que pertencem ao plano da natureza. Esta é a "tese geral da perspectiva natural" (general thesis of the natural standpoint):

\footnotetext{
2 “ . . I now also become aware that my own phenomenologically self-contained essence can be posited in an absolute sense, as I am the Ego who invests the being of the world which I so constantly speak about with existential validity, as an existence (Sein) which wins for me from my own life's pure essence meaning and substantiated validity. I myself as this individual essence, posited absolutely, as the open infinite field of pure phenomenological data and their inseparable unity, am the "transcendental Ego'” (Husserl, 1962, p. 11).
} 
A Tese Geral, de acordo com a qual o mundo real à minha volta é, em todo tempo, conhecido não meramente de um modo geral como algo apreendido, mas como um mundo factual que possui seu ser, que não consiste, evidentemente, em um ato, propriamente, em um julgamento articulado sobre a existência. Ele é e permanece algo todo o tempo em que a perspectiva é adotada, isto é, ele permanece persistentemente durante todo o curso de nossa vida de atividade natural. (Husserl, p. 96)

Da ideia da Tese Geral deriva o conceito de tético (thetic, thétique): tratase de uma ruptura, no processo significante, que estabelece uma identificação entre o sujeito e o objeto como condições da proposicionalidade:

Toda enunciação é tética, seja ela de uma frase ou palavra. Ela requer uma identificação; em outras palavras, o sujeito precisa separar-se de e através de sua imagem, de e através de seus objetos. Esta imagem e objetos necessitam primeiro ser postulados em um espaço que se torna simbólico porque conecta duas posições separadas, registrando-as ou redistribuindo-as em um sistema combinatório aberto. (Kristeva, 1974, p. 41-2, minha ênfase).

Portanto, o simbólico conecta as imagens virtuais do sujeito e do objeto. Dizendo de outra maneira, a relação entre um Ego transcendental, e os objetos apreendidos pela consciência, é postulada através da representação (signo) e do julgamento (sintaxe). O Sentido (a postulação do sujeito enunciante) é, então, a projeção da Significação (Bedeutung [ale.], signification [ing.], signification [fr.]) tal como presentificada pelo julgamento (Kristeva, 1974, p. 34). Em outras palavras, a Significação é a fala de um sujeito postulado (tético) em relação a um objeto. É evidente, portanto, que o sujeito husserliano depende, para sua existência, da estabilidade da sintaxe: o Sentido é a postulação do sujeito enunciante, e é sempre sintático (“ . . . [o] sentido [é] sempre gramatical, mais precisamente sintático", p. 58).

A fase tética é descrita pela psicanálise lacaniana, segundo Kristeva, através do estágio do espelho e da "descoberta” da castração (p. 46). De acordo com Lacan, a imagem especular é o "paradigma” do "mundo de objetos" (Lacan, 2002, p. 295). Ao projetar sua voz, nomeando um objeto ou sua imagem através do signo, a criança efetua a separação entre si e o objeto. A castração finaliza o processo de separação da mãe através do qual o sujeito torna-se significável, por 
meio de sua imago no espelho (significado) e do signo (significante). Assim, a fase tética é o lugar do Outro, a precondição da significação, portanto da linguagem (Kristeva, 1974, p. 48), e assim fica configurada a inseparabilidade entre a fase tética e a sintaxe.

Embora seja o portador da sintaxe, o sujeito falante está ausente dela. Quando este sujeito - o chora semiótico - reemerge, a postulação tética, o objeto denotado e a relação sintática entre eles são abalados. Isto foi o que ocorreu com a música "erudita" ocidental, a partir da virada do século XIX para o XX. Enquanto o Ego transcendental suprime o chora semiótico, o sujeito da enunciação produzido pela reaparição do chora eleva este chora à posição de significante. Esta materialidade, que se opõe à virtualidade das regras sintáticas, destrói este sistema de relações abstratas e faz o significante (sem significado) musical emergir em sua concretude. No entanto, há uma diferença entre a destruição da sintaxe musical para que este som possa emergir, e o uso idiossincrático do ruído, comparável ao delírio psicótico, na medida em que é solipsista e incapaz de se comunicar intersubjetivamente. A destruição da sintaxe tonal, sob a influência do semiótico, foi um processo socializado que desenvolveu-se progressivamente ao longo da história, e foi reabsorvido na sintaxe musical sob a forma do serialismo, conforme veremos a seguir.

As possibilidades do sistema tonal, desde sua instituição em inícios do século XVII até o final do XIX, foram exaustivamente exploradas pelos compositores. O recurso da modulação foi utilizado em todo o seu potencial de proporcionar surpresa e excitação: iniciando-se com modulações aos tons vizinhos, chegou até os tons mais afastados. A função dominante, ponto de cruzamento e acúmulo de dissonâncias, destacava-se por sua força expressiva e colorido. Esta estrutura funcionou como "ponte" ou "pivô" entre os eixos tonais (original e modulante) até que, em função de seu potencial expressivo claramente superior, em comparação às outras estruturas do sistema, gradualmente passou a tornar-se independente do sistema de relações. O foco na função dominante, com seu forte poder de atração sobre um novo centro tonal, implicava em modulações cada vez mais frequentes, e para tons cada vez mais afastados. Trechos em que se perdia a referência à tônica tornavam-se mais e mais estendidas, por volta da passagem do 
século XIX para o XX. Simultaneamente, os compositores passaram a romper também com a métrica, através do uso do rubato, uma maneira de flexibilizar o ritmo que foi levada às últimas consequências, não raro acompanhada de síncopas e poliritmia. Percebe-se, através destas alterações na linguagem socializada da música através da história, a motilidade do chora semiótico em sua irrupção sobre a sintaxe musical, desorganizando-a. Com estes desenvolvimentos, o tecido tonal foi-se esgarçando. Libertos do sistema relacional que os subordinava às outras funções tanto metricamente quanto frequencialmente, os acordes dissonantes puderam emergir para o primeiro plano e ser apreciados pelo seu som concreto.

O compositor Anton Webern (1883-1945) marcou com sua obra as mais radicais, fascinantes e influentes experiências de recusa à tonalidade e à métrica desta fase de ruptura. Webern foi discípulo de Schoenberg, como também Alban Berg o foi. Os três são considerados a "segunda escola vienense" (a primeira tendo sido formada por Haydn, Mozart e Beethoven), por terem revolucionado a escrita musical através do serialismo (método de composição através do uso nãohierárquico das doze notas musicais, apresentado publicamente por Schoenberg em 1923). Apesar de o criador do serialismo haver sido Schoenberg, uma figura reverenciada por Webern até às raias da idolatria, o mais consistente proponente da nova ordem musical foi Webern, que a intuiu anos antes de Schoenberg. Enquanto as composições de Schoenberg mostram fragmentos da antiga sintaxe (motivos, temas, etc.), indicando sua uma imaginação musical não inteiramente livre das convenções tonais; e enquanto Berg também não criou exclusivamente dentro dos parâmetros da nova música, Webern demonstrou-se à vontade no novo território. Como consequência, é o mais influente dos três, sendo uma marcante presença nos estilos de compositores avant-garde, como, p. ex., Boulez, Stockhausen e Dallapiccola.

Desde antes do ano de 1908, a música de Webern já vinha sendo crescentemente atonal; neste ano, no entanto, o compositor começou a escrever a música para catorze poemas de Stefan George, que marcou o abandono definitivo da tonalidade. As Seis Bagatelas para Quarteto de Cordas, Op. 9, escritas a partir de 1911, são portanto já inteiramente atonais, mas ainda não completamente 
seriais. Que Webern prenunciou a ideia do serialismo nesta obra, no entanto, não resta dúvida, de acordo com o escrito que deixou a respeito das Bagatelas:

Ao trabalhar nelas tive a sensação de que, uma vez que as doze notas tinham se esgotado, a peça estava terminada. Muito mais tarde eu percebi que isto era parte da evolução necessária. Escrevi a escala cromática em meu caderno de notas e toquei notas isoladas a partir dele . . Em uma obra, uma lei veio a ser: nenhuma nota deve re-ocorrer até que todos os doze sons tenham ocorrido. A coisa mais importante é que uma aparição dos doze sons dá à peça, à ideia, ao tema, uma cesura formal. (Webern, 1963, p. 51)

No entanto, segundo o musicólogo Richard Chrisman, "a análise da música, de início pelo menos, revela que Webern não parece estar a ordenar as notas em qualquer modo que pareça a composição serial surgida posteriormente" (Chrisman, 1979, p. 82). Esta música colocou dificuldades consideráveis para os analistas, considerando a quantidade apreciável de artigos escritos sobre ela - e em especial sobre a Bagatela no. 1 - tal como comenta outro renomado musicólogo, Allen Forte: “ . . . esta primeira peça da Opus 9 de Webern é, provavelmente, a mais complexa do conjunto, e não muitos autores têm se erguido para enfrentar os desafios que ela oferece" (Forte, 1994, p. 172). Os desafios encontrados pelos analistas dizem respeito às dificuldades em encontrar uma ordem lógica que explique as decisões de Webern a respeito dos muitos elementos desta música que escapam tanto à sintaxe tonal quanto à sintaxe serial. Trata-se de um momento em que a irrupção do semiótico sobre a linguagem já havia desorganizado a tonalidade, mas não havia ainda sido absorvida pela nova linguagem dodecafônica.

A respeito da Bagatela no. 1, Forte observa

. . . a ausência de óbvias repetições de formações mais longas de alturas e, correspondentemente, a evitação escrupulosa de temas e motivos tradicionais, a atenção extraordinária outorgada [à] dinâmica, ao modo de ataque, à articulação rítmica, e às mudanças expressivas de tempo cuidadosamente notadas - por exemplo, a instrução heftig no clímax dinâmico do movimento no c. 7. Adicionalmente, e de relevância especial para o presente artigo, são os extremos dos registros - notavelmente, o c $\$ 4$ no violino I no começo do c. 8 (p. 47) e o C grave do cello ao final do c. 6 (p36) ... (Forte, 1994, p. 174) 
Esta peça apresenta-se, portanto, como alta compressão de eventos em apenas dez compassos. Uma quantidade expressiva de efeitos instrumentais pizzicato, spiccato, col legno, am Griffbrett, am Steg, harmônicos, uso extensivo de Dämpfer, ou surdina - , juntamente com a grande variedade de registros, alterações no andamento e drásticas mudanças de dinâmica (de $p p$ a fff entre apenas dois compassos, 5-7) faz com que as características timbrais ganhem uma relevância inédita. Com isso, as notas como que se descolam do plano chapado de uma escuta linear aprisionada em um sistema de expectativas e previsibilidade, e atraiam irresistivelmente a atenção do ouvinte para sua superfície, para sua sensualidade. Quanto ao aspecto rítmico, inexiste pulso ou definição métrica. Fragmentos de melodia são delimitados por silêncios, dissolvendo qualquer expectativa teleológica produzida por relações sintáticas.

Ao ser incorporada à ordem simbólica (o que é inevitável a toda produção significante, e necessário se se espera que a obra exerça efeitos sobre a cultura), a partir da formalização da linguagem serial, esta nova prática reencontra o sujeito e o plano social. Tendo a sintaxe sido profundamente subvertida, o sujeito produzido por ela é colocado em processo, é desconstruído. A identidade garantida pela sintaxe - entra em crise, na proposição de Kristeva:

esta heterogeneidade à significação opera através, a despeito, e excessivamente com relação a ela, e produz efeitos "musicais" mas também sem sentido na linguagem poética que destroem não apenas crenças aceitas e significações, mas, em experimentos radicais, a própria sintaxe, aquela garantia da consciência tética (do objeto significado e do ego) (Kristeva, 1980, p. 133).

A música, agora transformada em texto - uma rede aberta de conexões indiciais, um lugar virtual onde o processo significante pode ser visto em ação passa a ser também uma prática significante intertextual. A multiplicação de posições, neste tipo de produção intertextual, existe simetricamente a um destinatário capaz de identificar-se com elas.

A matriz da enunciação em uma narrativa tende a centralizar-se em uma posição axial que é explicitamente ou implicitamente denominada "eu" ou "autor" - uma projeção do papel paternal na família. Embora seja axial, esta 
posição é móvel; ela assume todos os papéis possíveis das relações intra- e inter- familiais, e é tão mutável quanto uma máscara. Correlativamente, esta posição axial pressupõe um destinatário que é solicitado a reconhecer-se nos múltiplos "eus" do autor. Poderíamos dizer que a matriz da enunciação estrutura um espaço subjetivo no qual, estritamente falando, não há um sujeito único e fixo; mas neste espaço, o processo significante é organizado, isto é, recebe um sentido, tão logo encontre os dois fins da cadeia comunicativa, e, no intervalo, as várias cristalizações de "máscaras" ou "protagonistas" correspondentes às geminações do processo de significação contra as estruturas parentais-sociais. (Kristeva, 1974, p. 87)

O ponto crucial deste movimento é a relação entre a intertextualidade produzida por tipos de produções musicais que possibilitam o entrelaçamento, a tessitura, o texto de diferentes posições enunciativas - e a subjetividade do destinatário:

[s]e somos leitores de intertextualidade, devemos ser capazes do mesmo colocar-em-processo de nossas identidades, capazes de nos identificarmos com os diferentes tipos de textos, vozes, e sistemas semânticos, sintáticos e fônicos em ação em um dado texto. Também devemos ser capazes de reduzirmo-nos a zero, ao estado de crise que é, talvez, a pré-condição necessária ao prazer estético, ao ponto de emudecimento de que Freud fala, de perda do sentido, antes que possamos entrar em um processo de livre associação, reconstituição de sentidos diversos, ou tipos de conotações que são quase indefiníveis - um processo que é uma recriação do texto poético. (Kristeva apud Guberman, 1996, p. 190)

Em 1911, quando Schoenberg escreveu suas Six Little Piano Pieces, Op. 19, havia já cinco anos em que Webern acompanhava seu mestre com devoção filial, emulando-o a ponto de correr o risco de tornar-se um imitador. Escutando a nova peça, Webern notou que alguns movimentos careciam de maior contraste. Naquele momento, a atonalidade era um terreno descoberto palmo a palmo, sem que se soubesse onde chegaria. Schoenberg deu pouca importância ao seu novo trabalho, enquanto Webern debruçou-se sobre o problema do contraste, escrevendo, mais tarde no mesmo ano, alguns movimentos da Op. 9, que considerou seu segundo quarteto de cordas, e que viria a ser as Seis Bagatelas. Este trabalho significou a superação do mestre, no sentido de estabelecer uma ruptura ainda mais rigorosa com o sistema tonal, em relação àquela produzida por 
Schoenberg. Foi um trabalho de transformação pessoal, e que também foi seguido por uma transformação radical da linguagem musical que vigorava havia 300 anos. Depois das Bagatelas, Webern caminhava resolutamente para suas experiências de formalização da linguagem serial, tal como já se podia notar através do seu escrito citado acima, e que prenunciava a nova técnica 12 anos antes de Schoenberg fazer seu anúncio público. As Bagatelas podem ser consideradas, portanto, como este elo que liga e separa duas linguagens radicalmente diferentes. Pura motilidade pulsional ainda não absorvida pela ordem simbólica, que ainda esperaria os anos 1920 para ver a codificação da nova linguagem através do dodecafonismo, as Bagatelas demonstram poderosamente como a concretude da superfície sonora, escutada pela primeira vez na música ocidental, provocou duradouros efeitos subjetivantes. Observamos portanto, já na Bagatela no. 1 de Webern, elementos de uma nova música, que produzia um novo modo de ouvir e um novo modo de ser: uma outra prática do dizer.

\section{Referências}

ARISTÓTELES. Política. Introdução, tradução e notas de Manuela García Valdés. Madri: Gredos, 1988.

BENT, I.; POPLE, A. Analysis, §ll: history. 2. 1750-1840. Grove Music Online. L. Macy (ed.) (Acessado em 25 de Fevereiro de 2006), $<$ http://www.grovemusic.com> 2006.

CHRISMAN, R. Anton Webern's "Six bagatelles for string quartet," Op. 9: The unfolding of intervallic successions. Journal of Music Theory, Vol. 23, No. 1 (Spring, 1979), p. 81-122.

FORTE, Allen. An octatonic essay by Webern: No. 1 of the "Six Bagatelles for String Quartet," Op . 9. Music Theory Spectrum, Vol. 16, No . 2 (Autumn, 1994), p. 171-195.

GRAUER, V. Montage, realism, and the act of vision. http://doktorgee.worldzonepro.com/MontageBook/MontageBook-part4.htm. Acessado em 8/3/2006.

GUBERMAN, R. M. (ed.). Julia Kristeva interviews. New York: Columbia UP, 1996. 
HUSSERL, E. Ideas: general introduction to pure phenomenology. Tradução W.R. Boyce Gibson. New York: Collier-Macmillan, 1962. Título original: Ideen zu einer reinen Phänomenologie und phänomenologischen Philosophie.

KRISTEVA, J. Desire in language: a semiotic approach to literature and art. New York: Columbia UP, 1980.

- La révolution du langage poétique; I'avant-garde à la fin du XIXe siècle: Lautréamont et Mallarmé. Paris: Éditions du Seuil, 1974.

LACAN, J. Écrits: a selection. Tradução Bruce Fink. Nova York: W.W. Norton, 2002. Título original: Écrits.

NEDER, A. O estudo cultural da música popular brasileira: dois problemas e uma contribuição. Per Musi, Belo Horizonte, n.22, 2010, p.181-195.

PLATÃO. A república. Tradução: Maria Helena da Rocha Pereira. Lisboa: Fundação Calouste Gulbenkian. 3a . ed., 1980.

WEBERN, A. The path to the new music. Willi Reich (ed.). Traduzido por Leo Black. Bryn Mawr, Pa.: Theodore Presser Co., 1963. 